\begin{tabular}{|c|c|}
\hline Title & Extinction limits of an ammonia/air flame propagating in a turbulent field \\
\hline Author(s) & Ichimura, Ryo; Hadi, Khalid; Hashimoto, Nozomu; Hay akawa, A kihiro; Kobay ashi, Hideaki; Fujita, Osamu \\
\hline Citation & $\begin{array}{l}\text { Fuel, 246, 178-186 } \\
\text { https:/doi.org/10.1016/.fuel.2019.02.110 }\end{array}$ \\
\hline Issue Date & $2019-06-15$ \\
\hline Doc URL & http:/hdl .handle.net/2115/81845 \\
\hline Rights & $\begin{array}{l}\text { @2019. This manuscript version is made avail able under the CC-BY-NC-ND } 4.0 \text { license } \\
\text { http://creativecommons.org/icenses/by-nc-nd/4.0/ }\end{array}$ \\
\hline Rights(URL) & http://creativecommons.org/icenses/by-nc-nd/4.0/ \\
\hline Type & article (author version) \\
\hline File Information & Revesed_manuscript.pdf \\
\hline
\end{tabular}

Instructions for use 


\title{
Extinction limits of an ammonia/air flame propagating in a turbulent field
}

Ryo Ichimura ${ }^{1}$, Khalid Hadi $^{1}$, Nozomu Hashimoto ${ }^{1}$, Akihiro Hayakawa ${ }^{2}$, Hideaki Kobayashi $^{2}$, Osamu Fujita ${ }^{1}$

1. Division of Mechanical and Space Engineering, Graduate School of Engineering, Hokkaido University, Kita13 Nishi8, Kita-ku, Sapporo, Hokkaido 060-8628, Japan

2. Institute of Fluid Science, Tohoku University, 2-1-1 Katahira, Aoba-ku, Sendai, Miyagi 980-8577, Japan

Correspondence:

\author{
Nozomu HASHIMOTO \\ Division of Mechanical and Space Engineering, Graduate School of Engineering, \\ Hokkaido University, Kita 13 Nishi 8, Kita-ku, Sapporo, 060-8628, Japan \\ Phone: +81-11-706-6386 \\ FAX: $\quad+81-11-706-6386$ \\ E-mail: nozomu.hashimoto@eng.hokudai.ac.jp
}

Declarations of interest: This work was supported by JST research promotion program Sakigake (PRESTO) Grant Number JPMJPR1542 and the Collaborative Research Project of the Institute of Fluid Science, Tohoku University. 


\begin{abstract}
Ammonia, which does not emit carbon dioxide even when it is burned, is expected as a new carbon-free fuel to replace coal and natural gas used in thermal power plant. However, the turbulent flame propagation characteristics have yet to be extensively investigated. This study aimed to clarify the extinction limits of ammonia/air flame in turbulent fields. To achieve this aim, the spherical flame propagation experiments using a fan-stirred constant volume vessel were conducted. The results revealed the unique feature of extinction limit of ammonia in a turbulent field. The ammonia/air mixture with a 0.9 equivalence ratio can propagate at the highest turbulence intensity even though the laminar burning velocity reaches a maximum around an equivalence ratio of 1.1. The fuel-lean mixture can propagate at high turbulence intensity because of the effect of Lewis number. For a lean ammonia/air mixture that has a Lewis number smaller than unity, the local burning velocity increases by the diffusional-thermal instability. On the other hand, the local burning velocity in rich ammonia/air mixtures with a Lewis number larger than unity did not increase in the turbulent field, and the flame was easily extinguished. Because of the diffusional-thermal instability, the turbulence Karlovitz number at the flame extinction limit increases as the Markstein number decreases. The obtained findings from this study can contribute to the optimal design of gas turbines fueled by ammonia as well as the safety use of ammonia.
\end{abstract}

Key words: Ammonia; Turbulent flame; Extinction limits; Turbulence intensity; Lewis number; Markstein number 


\section{Introduction}

Ammonia is considered as one of the most promising candidates as a hydrogen energy carrier in Japan. Ammonia can be produced from renewable energy sources and various studies regarding the production of ammonia have been conducted [1-5]. Since the ammonia molecule has no carbon atom, it can be a $\mathrm{CO}_{2}$-free fuel if it was produced from renewable energy sources. The most significant advantage that ammonia has as an energy carrier is its ease of transport and storage due to its characteristics, i.e., ammonia can be liquified at room temperatures when it is pressurized. Because of these advantages, ammonia represents a potentially valuable $\mathrm{CO}_{2}$-free fuel in fuel cells [6, 7], gas turbines [8-13], boilers, or internal-combustion engines [14-17]. Although the overall thermal efficiency increases when ammonia is used in fuel cells, the development of practical large-scale fuel cells that use ammonia as a fuel have yet to be fully developed. On the other hand, if ammonia can be directly combusted as a fuel in a more conventional large-scale thermal power plant, it would not take much time be begin utilizing ammonia as an energy source. Recently, various fundamental studies have been conducted on the laminar burning velocity [18-24], explosion behavior [25], chemical kinetics [26-32], extinction characteristics [33], effects of plasma [34], and stabilization of turbulent ammonia/air flame [35]. Previous researches showed that the laminar burning velocity of ammonia is much lower than that of general hydrocarbon fuels, such as methane and propane. Although the laminar flame propagation characteristics of ammonia/air mixtures have been investigated in many studies [18-24], the turbulent flame propagation characteristics of ammonia/air mixture have yet to be extensively investigated. For the efficient development of gas turbines that use ammonia as a fuel, the flame propagation characteristics in the turbulent field, which is different from that in the laminar flow field, must be investigated in detail.

In this study, the spherical flame propagation characteristics in turbulent fields were investigated using a fanstirred closed vessel. Combustion experiments with various equivalence ratios and turbulence intensities were conducted, and the effects of changing these values on the propagation limit of the ammonia/air mixtures at atmospheric pressure were evaluated. The results of this study revealed the unique flame propagation characteristics of ammonia in a turbulent field.

\section{Experimental apparatus and procedures}

Fig. 1 shows a schematic diagram of the experimental apparatus used in this study. Experiments were carried out using a constant volume combustion chamber that has a volume of about 6.2 L [36]. The interior of the combustion chamber was spherical with a diameter of $200 \mathrm{~mm}$. Mixture was ignited by an electric spark, and the spark electrode with a diameter of $1.8 \mathrm{~mm}$ was inserted into the center of the chamber with the spark gap set to $3 \mathrm{~mm}$. A capacitor discharge ignition (CDI) circuit was adopted for spark ignition, and the electrostatic energy that was charged in the capacitors of the CDI circuit was set to $2.8 \mathrm{~J}$. The two fans were mounted on the top and bottom of the chamber and were driven by electric motors (Maxon Motor, RE40), and the rotation speed was controlled by the motor controllers (Maxon Motor, ESCON 50/5).

Flame propagation was observed through quartz windows that have a diameter of $50 \mathrm{~mm}$ and was recorded by Schlieren photography. These optical windows were located opposite each other. Schlieren photography was taken by a high-speed camera (Phantom, Miro C210) in combination with an LED light source (HAYASHI-REPIC CO., 
LTD., LA-HDF5010C). To create a spotlight effect, a pinhole was mounted in front of the light source. A lens (Nikon,

AI Nikkor $50 \mathrm{~mm}$ f/1.2S) was mounted on the high-speed camera, and the resolution of the Schlieren photography was $512 \times 512$ at a frame rate of 3500 fps.

The pressure inside the chamber during flame propagation was measured with a pressure sensor (Valcom, VPRTF-A4-(-0.1-2 MPa) S-5, P1), and pressures were recorded by a memory recorder (GRAPHTEC, GL900) with a sampling interval of $10 \mu \mathrm{s}$.

Ammonia was used as the fuel, and dry air was used as the oxidizer. Table 1 shows the experimental conditions. The turbulence intensity, $u^{\prime}$, was estimated from the relationship between the rotational speed of the two fans, and the turbulence intensity measurements were obtained by the particle image velocimetry (PIV), which is described later. The equivalence ratio, $\phi$, was varied from 0.6 to 1.3. The mixture was prepared by the partial pressure of ammonia and air with a pressure sensor (Valcom, VPRTF-A4-(-0.1-1 MPa)-5, P2). In all experiments, the initial pressure and temperature were $1 \mathrm{~atm}$ and $298 \mathrm{~K}$, respectively. After filling the ammonia/air mixture, it was thoroughly stirred by the two fans installed in the combustion chamber, and a homogeneous mixture was prepared. In the laminar combustion experiments, the rotation of the two fans was halted after enough stirring, i.e. over $5 \mathrm{~min}$, was conducted, and 5 min after stopping the fans, the mixture was ignited. By contrast, in the turbulent combustion experiment, the mixture was ignited while the two fans were running. All the experiments were carried out at least six times under

Table 1. Experimental condition of ammonia/air premixture combustion

\begin{tabular}{ll}
\hline Equivalence ratio, $\phi(-)$ & $0.6,0.7,0.8,0.9,1.0,1.1,1.2,1.3$ \\
Turbulence intensity, $u^{\prime}(\mathrm{m} / \mathrm{s})$ & $0.32,0.65,0.97,1.29,1.61$ \\
Initial mixture pressure (atm) & 1 \\
Initial mixture temperature (K) & 298 \\
\hline
\end{tabular}

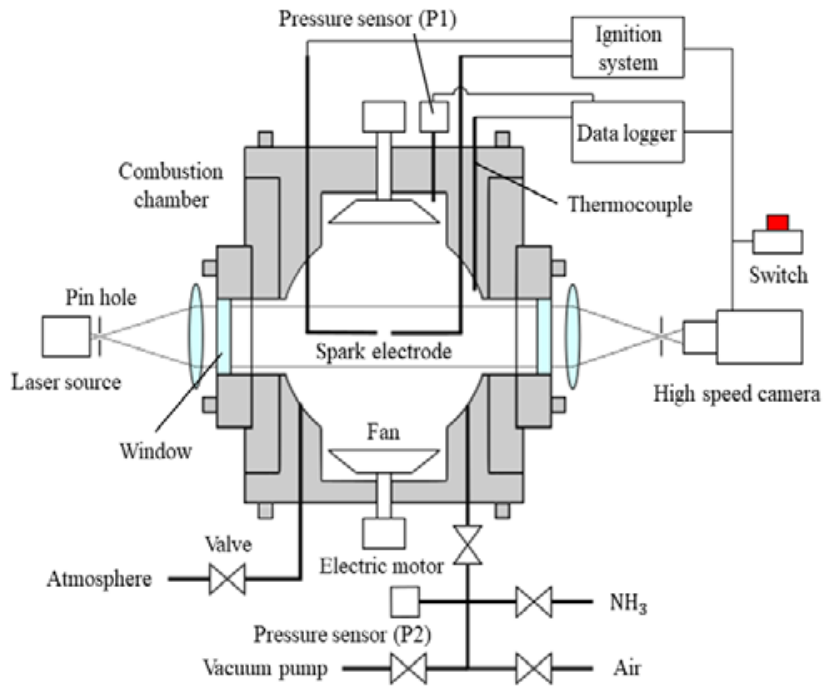

Fig. 1 Schematic figure of experimental apparatus

Table 2.Properties of the ammonia/air mixtures

\begin{tabular}{ccccccccc}
\hline$\phi[-]$ & $\rho_{u}\left[\mathrm{~kg} / \mathrm{m}^{3}\right]$ & $\rho_{b}\left[\mathrm{~kg} / \mathrm{m}^{3}\right]$ & $\lambda\left[10^{-3} \mathrm{~W} / \mathrm{m} / \mathrm{K}\right]$ & $c_{p}[\mathrm{~J} / \mathrm{kg} / \mathrm{K}]$ & $\alpha$ & {$\left[10^{-5} \mathrm{~m}^{2} / \mathrm{s}\right]$} & $v\left[10^{-5} \mathrm{~m}^{2} / \mathrm{s}\right]$ & $L e[-]$ \\
\hline 0.6 & 1.115 & 0.202 & 27.08 & 1099 & 2.210 & 1.564 & 0.95 \\
0.7 & 1.105 & 0.183 & 27.19 & 1114 & 2.210 & 1.562 & 0.95 \\
0.8 & 1.095 & 0.168 & 27.29 & 1128 & 2.209 & 1.561 & 0.94 \\
0.9 & 1.087 & 0.156 & 27.39 & 1141 & 2.208 & 1.559 & 0.93 \\
1.0 & 1.078 & 0.147 & 27.48 & 1155 & 2.208 & 1.558 & $=$ \\
1.1 & 1.070 & 0.147 & 27.56 & 1168 & 2.207 & 1.557 & 1.10 \\
1.2 & 1.062 & 0.148 & 27.64 & 1180 & 2.205 & 1.556 & 1.10 \\
1.3 & 1.055 & 0.150 & 27.71 & 1192 & 2.204 & 1.554 & 1.09 \\
\hline
\end{tabular}


each condition.

Table 2 shows the properties of the ammonia/air mixture. Here, $\rho_{u}$ and $\rho_{b}$ present the unburned mixture density and burned gas density, respectively. The densities were evaluated using the equilibrium calculation from the NASA computer program Chemical Equilibrium with Applications [37]. $\lambda, c_{p}, \alpha, v$, and Le are the thermal conductivity, specific heat at constant pressure, thermal diffusivity, kinematic viscosity, and the Lewis number, respectively, which were calculated using the Dandy research group's website at Colorado State University [38]. As shown in Table 2, the Lewis number of fuel-lean mixtures is lower than unity and that of fuel-rich mixtures are higher than unity.

\section{Unstretched laminar burning velocity and Markstein number}

\subsection{Analysis of laminar flame}

In the laminar combustion experiment, the flame propagated through the entire combustion chamber under equivalence ratio conditions from 0.7 to 1.2 .

The radius of the spherical propagating laminar flame at each time interval was determined from the captured Schlieren images, and the flame propagation velocity, $S_{n}$, evaluated by Eq. (1):

$$
S_{n}=\frac{d r_{s c h}}{d t}
$$

where $r_{s c h}$ is the equivalent radius obtained from the area of the flame images, and $t$ is time. Since the spherically shaped flame generated with the premixed fuel has a curvature, the influence of flame stretch must be considered. In the case of a spherical propagation of flames, the flame stretch rate, $\varepsilon$, is defined by Eq. (2) $[18,39,40]$ :

$$
\varepsilon=\frac{1}{A} \cdot \frac{d A}{d t}=\frac{2}{r_{s c h}} \cdot \frac{d r_{s c h}}{d t},
$$

where $A$ ( $=4 \pi r_{s c h}{ }^{2}$, for spherically flame) is the front of the flame area. The flame propagation velocity is different from the unstretched flame propagation velocity due to flame stretch. According to asymptotic analysis, the difference between the unstretched flame propagation velocity, $S_{s}$, and stretched flame propagation velocity, $S_{n}$, can be considered to be proportional to the flame stretch rate, as shown by Eq. (3) [18, 39, 40]:

$$
S_{s}-S_{n}=L_{b} \cdot \varepsilon,
$$

where $L_{b}$ is the burned gas Markstein length. The unstretched flame propagation velocity, $S_{S}$, can be obtained by the extrapolation of $\varepsilon \rightarrow 0$ (or $r_{s c h} \rightarrow \infty$ ), and the unstretched laminar burning velocity, $S_{l}$, can be calculated by Eq. (4) $[18,39,40]$ :

$$
S_{l}=\frac{\rho_{b}}{\rho_{u}} \cdot S_{s},
$$

where $\rho_{u}$ and $\rho_{b}$ are the unburned mixture density and burned gas density, respectively.

Eq. (3) can be rewritten as dimensionless using the unstretched laminar burning velocity and the preheat zone thickness, $\delta_{l}$, as shown by Eq. (5):

$$
\frac{S_{l}-S_{n}}{S_{l}}=K \cdot M a,
$$


where $K\left(=\alpha \delta_{l} / S_{l}\right)$ is the flame stretch factor and $M a\left(=L / \delta_{l}\right)$ is the Markstein number [41]. The preheat zone thickness of laminar flames is determined by $\delta_{l}=\lambda / \rho_{u} c_{p} S_{l}$, where $\lambda$ and $c_{p}$ are the thermal conductivity and specific heat at a constant mixture pressure. The unstretched laminar burning velocity, $S_{l}$, was calculated from the

92 numerical simulation by Okafor's mechanism [22].

\subsection{Experimental results}

Experiments of laminar flames of ammonia/air mixture were conducted at various equivalence ratios ranging

96 from 0.6 to 1.3. Fig. 2 shows the Schlieren images of ammonia/air mixture flames at an equivalence ratio of $\phi=$ 97 0.8, 1.0, 1.2. Although the flames moved to the upper end of the combustion chamber due to a buoyancy effect, the

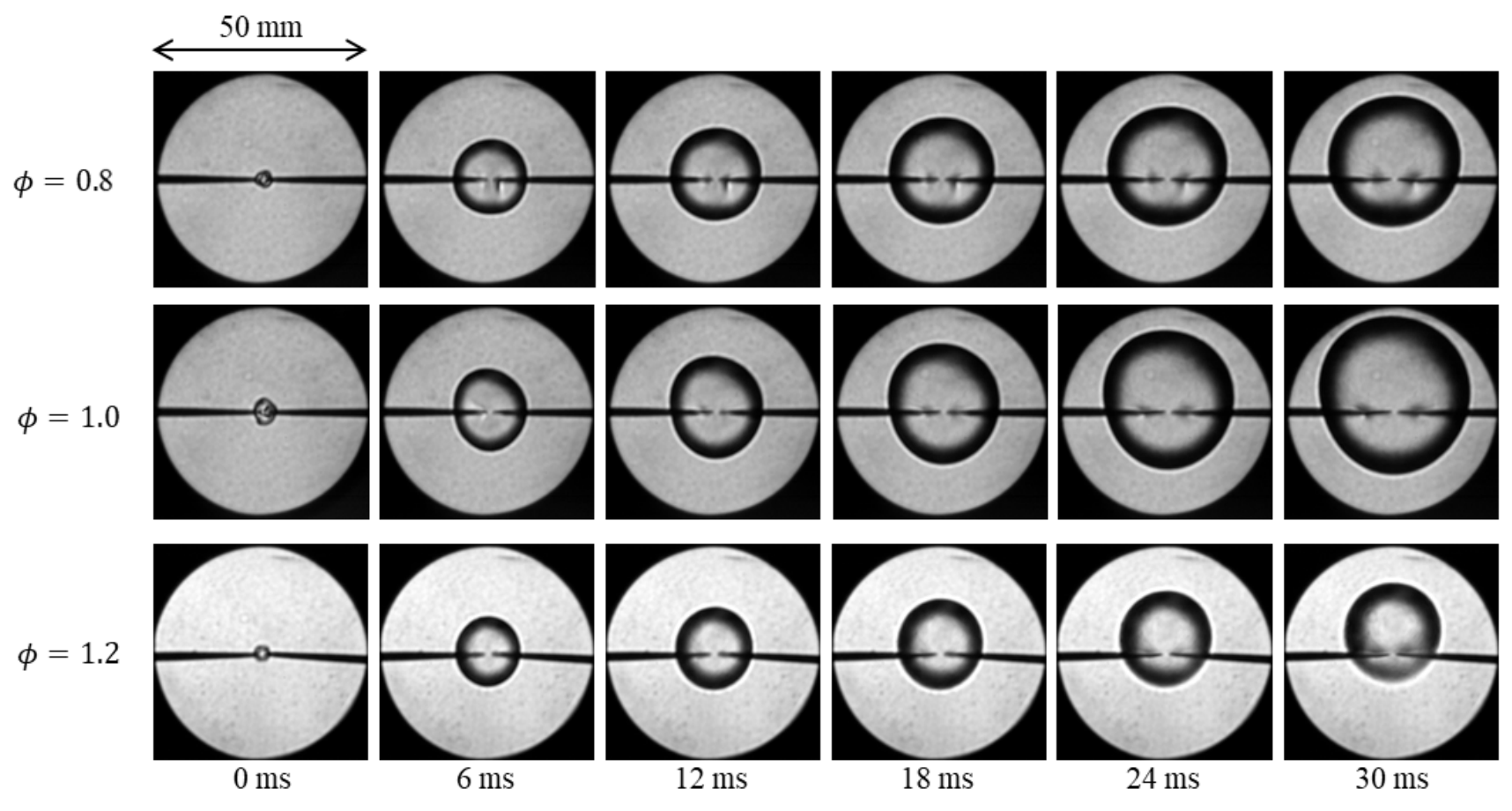

Fig. 2 Schlieren images of ammonia/air mixture laminar flames at various equivalence ratios

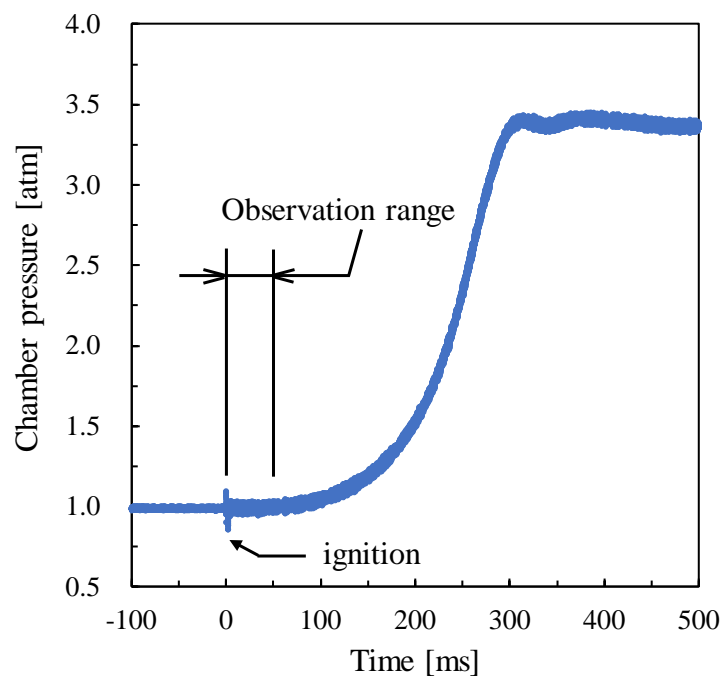

Fig. 3 Pressure history inside the combustion chamber for $\phi=1.0$ 
flames were almost spherical at each equivalence ratio when the mixture was able to propagate. The edges of the flames in the case of $\phi=0.8-1.1$ were clearly observed so that the equivalent flame radius was relatively easy to calculate. However, in the case of $\phi=0.7$ and 1.2, the bottom boundary of the flame was not entirely obvious.

Fig. 3 shows the time history of pressure for $\phi=1.0$ inside the combustion chamber. The pressure was almost constant at an atmospheric pressure from the point of ignition to $50 \mathrm{~ms}$. Therefore, the pressure in the chamber during the flame propagation within the observation range of the flame radius measurement was assumed to be atmospheric pressure.

Fig. 4 shows the variations of unstretched laminar burning velocities, $S_{l}$, with equivalence ratio, $\phi$. The unstretched laminar burning velocity was at its maximum near $\phi=1.1$. The flame propagation was observed for equivalence ratios from 0.7 to 1.2. However, under the conditions of $\phi=0.7$ and 1.2, the unstretched laminar burning velocity could not be obtained because the flame surface was unclear because of the large buoyancy effect. Fig. 4 also shows the results obtained from experiments by Hayakawa et al. [18] using the same method to calculate the unstretched laminar burning velocity. The results obtained experimentally by Takizawa et al. [20], Pfahl et al. [21] and Zakaznov et al. [42] are also plotted in Fig. 4. It is important to note that all these studies obtained a laminar burning velocity for an ammonia/air mixture with each method that revealed similar results. In addition, Fig. 4 also shows the results of numerical simulation of the laminar burning velocity using Okafor's mechanism [22]. From these results, the reproducibility of the flame propagation experiment of an ammonia/air mixture was confirmed in these experimental conditions of our study.

Fig. 5 shows the relationship between the Markstein number, $M a$, and the equivalence ratio, $\phi$. The Markstein number increased with increases in the equivalence ratio. This trend is similar to the premixed methane/air flame [43] and premixed hydrogen/air flame [44]. On the other hand, the premixed iso-octane/air flame [18] and premixed propane/air flame [45] displayed an opposite trend. The value of the Markstein number for $\phi=0.8$ and 0.9 is negative. In the case of fuel-lean ammonia/air mixtures with a Lewis number less than unity, the Markstein number has a negative value; therefore, the unstretched laminar burning velocity was lower than stretched laminar burning velocity. On the other hand, the unstretched laminar burning velocity is higher than the stretched laminar burning

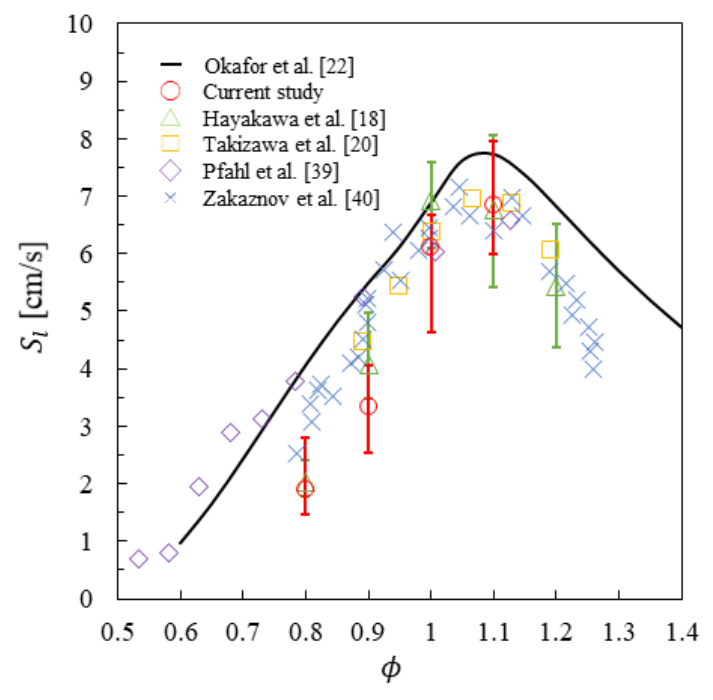

Fig. 4 Experimental results of the variations of unstretched laminar burning velocities, $S_{l}$, with equivalence ratio, $\phi$

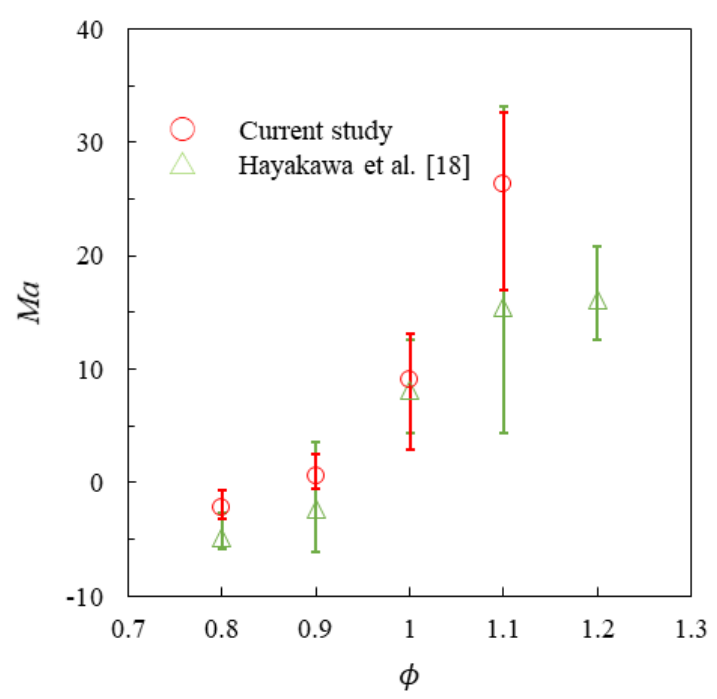

Fig. 5 Relationship between Markstein number, $M a$, and equivalence ratio, $\phi$ 
velocity of fuel-rich mixture because of the positive Markstein number.

\section{Turbulence characteristics}

To evaluate the turbulence characteristics, such as turbulence intensity and turbulence scales, PIV measurement was conducted. The analysis conditions are shown in Table 3. The observation ranges were set to $64.9 \mathrm{~mm} \times 86.5$ $\mathrm{mm}$ (large) and $8.6 \mathrm{~mm} \times 11.5 \mathrm{~mm}$ (small) for analysis in wide area measurement and with high resolution. The relationship between the turbulence intensity, $u^{\prime}$, and the fan rotation speed, $N$, is shown in Fig. 6 . The turbulence intensity was generally proportional to the fan rotation speed. The turbulence intensity was estimated from the fan rotation speed to determine the experimental conditions.

To analyze the turbulent field, the longitudinal integral length scale, the longitudinal Taylor microscale and the Kolmogorov length scale were evaluated from the result of PIV measurement.

The longitudinal integral length scale was calculated from the measurement of the large field. The longitudinal correlation coefficients, $R_{11}(r)$, in terms of separation distance, $r$, were calculated using the fluctuation component of velocity. Fig. 7 shows $R_{11}(r)$ for all fan rotation speeds for large measurement field. The measured $R_{11}(r)$ was approximated by one exponential function, as expressed by Eq. (6) [40]:

$$
R_{11}(r)=\exp \left(-p r^{q}\right)
$$

where the constants $p=7.80 \times 10^{-3}$ and $q=1.54$ were determined from least-square fitting. The longitudinal integral length scale, $L_{f}$, is defined as the integration of $R_{11}(r)$ with respect to $r$ from zero to infinity. The integration can be calculated using the Gamma function, $\Gamma$, as expressed by Eq. (7):

$$
L_{f}=\int_{0}^{\infty} R_{11}(r) d r=p^{-1 / q} \cdot \Gamma\left(1+\frac{1}{q}\right) .
$$

Table 3. Experimental condition of PIV measurement

\begin{tabular}{|l|l|l|}
\hline Measurement field & Pressure $(\mathrm{atm})$ & Fan rotation speed $(\mathrm{rpm})$ \\
\hline Small $(8.6 \mathrm{~mm} \times 11.5 \mathrm{~mm})$ & 1 & $500,1000,1500,2000$ \\
Large $(64.9 \mathrm{~mm} \times 86.5 \mathrm{~mm})$ & 1 & $500,1000,1500,2000$ \\
\hline
\end{tabular}

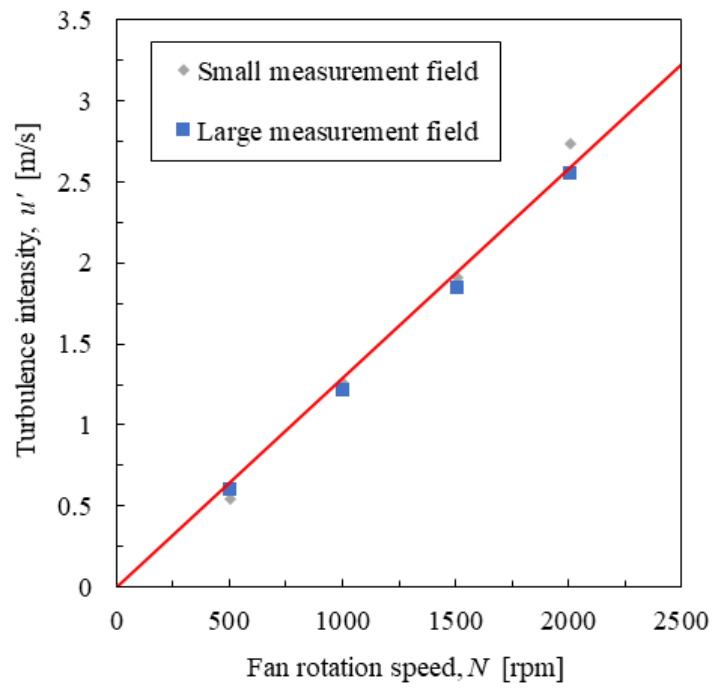

Fig. 6 Relationship between the turbulence intensity, $u^{\prime}$, and the fan rotation speed, $N$ [36]

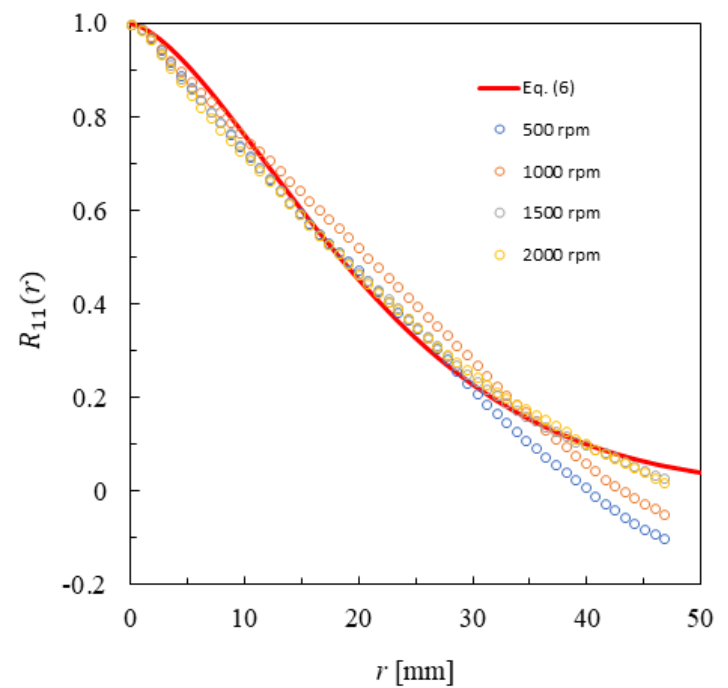

Fig. 7 Variation of longitudinal velocity correlation coefficient, $R_{11}(r)$, with distance, $r$ [36] 
144 The longitudinal integral length scale, $L_{f}$, was calculated as $L_{f}=20.9 \mathrm{~mm}$ regardless of the turbulence intensity 145 [36].

146 The longitudinal Taylor microscale and Kolmogorov length scale were calculated from the measurement of the small field. The longitudinal Taylor microscale, $\lambda_{f}$, and Kolmogorov length scale, $\eta_{k}$, are defined by Eqs. (8) and 148 (9), respectively:

where $u^{\prime}$ and $v$ are the turbulence intensity and the kinematic viscosity and $u_{i, j}$ shows the gradient of the velocity 152 fluctuation component, i.e., the differentiation of $u_{i}$ with respect to $j$ direction and “-” represents the ensemble value. The longitudinal Taylor microscale obtained by Eq. (8) is plotted in Fig. 8(a), and the Kolmogorov length scale obtained by Eq. (9) is plotted in Fig. 8(b).

The PIV measurements were only conducted in air under the experimental conditions summarized in Table 3. However, the actual experiments were conducted with an ammonia/air mixture. The physical properties, such as the kinematic viscosity of an ammonia/air mixture are different from pure air. For small scale measurements, the difference of these values should be considered, and thus, to consider the physical properties of the ammonia/air mixture, the following formulas were employed:

$$
\eta_{k}=\left(\frac{A_{0}}{15} \cdot \frac{v^{3}}{u^{\prime 3}} \cdot L_{f}\right)^{1 / 4},
$$

where $A_{0}$ is an empirical constant and $L_{f}$ is the longitudinal integral length scale obtained by Eq. (7). An empirical constant, $A_{0}$ was approximated by the least squares method from the result at each scale by Eqs. (8) and (9), and
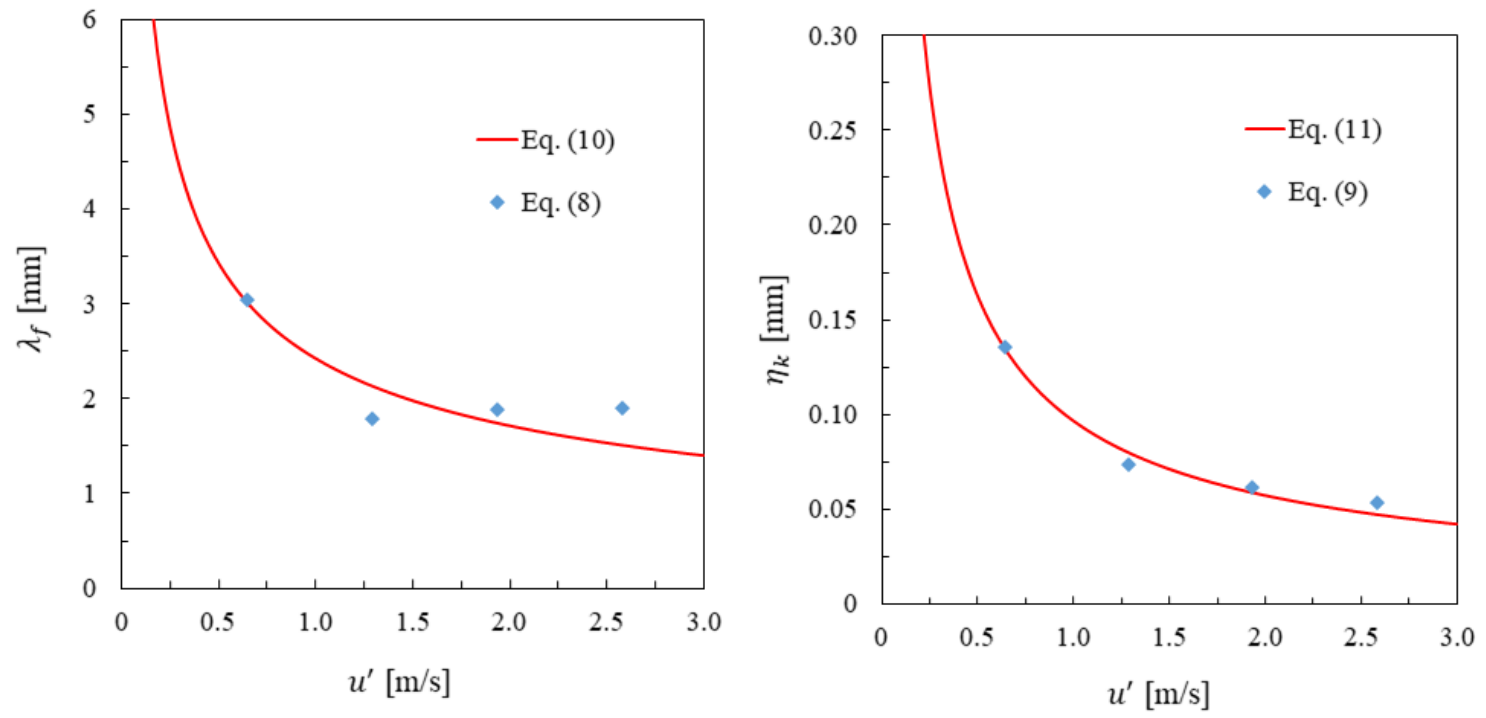

Fig. 8 Variations of (a) longitudinal Taylor microscale, $\lambda_{f}$, and (b) Kolmogorov length scale, $\eta_{k}$, with turbulence intensity, $u^{\prime}$ 
$164 A_{0}$ was calculated as 18.5. The longitudinal Taylor microscale according to Eq. (10) with $A_{0}=18.5$ is shown in 165 Fig. 8(a). Similarly, the Kolmogorov length scale according to Eq. (11) with $A_{0}=18.5$ is also shown in Fig. 8(b). 166 The results estimated from the calculations are close to the results from PIV measurements on both scales. By 167 assuming the empirical constant, $A_{0}$, the values did not change significantly regardless of the mixture gas, and thus, 168 the Taylor microscale can be calculated for any gas mixture. Therefore, the longitudinal Taylor microscale and 169 Kolmogorov length scale of ammonia/air mixtures were determined by Eqs. (10) and (11) with $A_{0}=18.5$ and $L_{f}=$ $17020.9 \mathrm{~mm}$. The longitudinal Taylor microscale, which was calculated in this section, was used to obtain the turbulence Karlovitz number, which is described later.

The energy spectrum function of turbulence, $E(k)$ was calculated by the following equation,

$$
E(k)=\frac{k^{2}}{\pi} \int_{0}^{\infty} r^{2} u^{\prime 2} R_{11}(r) \cdot\left(\frac{\sin k r}{k r}-\cos k r\right) d r,
$$

where $k$ is wavenumber, and $r$ is separation distance, and $u^{\prime}$ is turbulence intensity, and $R_{11}(r)$ is the longitudinal correlation coefficients [46]. Fig. 9 shows the energy spectrum function of turbulence divided by total

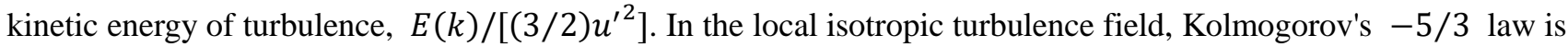
common for the inertial sub-region. Although there is some discrepancy, the inclination of the slope of the inertial sub-region is close to $-5 / 3$.

\section{Experiments of turbulent flame}

\subsection{Extinction limits of turbulent flame}

Flame propagation experiments using ammonia/air mixtures were carried out in a turbulent flow field. Fig. 10 shows the flame propagation probability map of the ammonia/air flames at the turbulence intensity for each equivalence ratio. In this map, the turbulence intensity with $u^{\prime}=0 \mathrm{~m} / \mathrm{s}$ shows the laminar combustion experiment, and the other turbulence intensity cases show the turbulence combustion experiments. In the case of the combustion experiments, the same result was not necessarily obtained under the same conditions. Therefore, the flame propagation probabilities were organized into four categories, i.e., the circle plots for $100 \%$ propagation, the square plots for $50-99 \%$ propagation, the triangle plots for $1-49 \%$ propagation, and the cross-mark plots for $0 \%$ propagation.

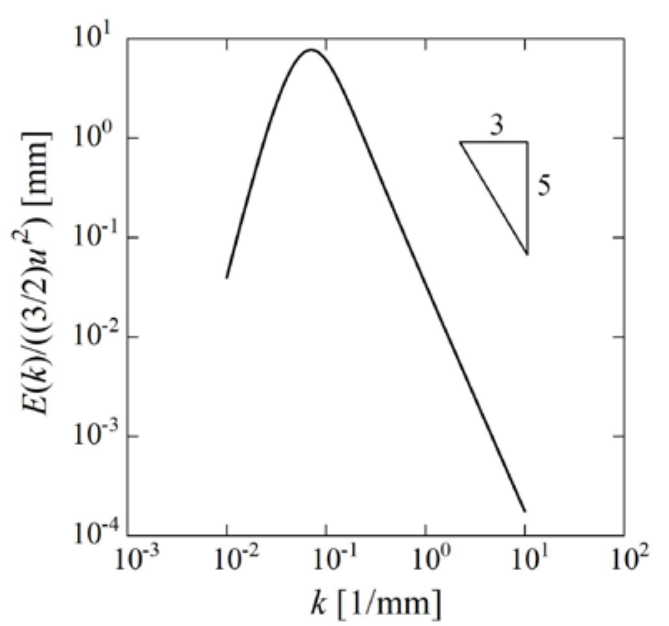

Fig. 9 Variation of energy spectrum function of turbulence, $E(k)$, with wavenumber, $k$ 
The probability was calculated using the results with more than six tests for the same conditions. In some experiments with a high degree of turbulence intensity, the flame propagated while the flame kernel was blown away from the center of the combustion chamber after ignition. That type of result was defined as the flame propagation for the purposes of this study. From the results of the flame propagation experiments in quiescent environment, the laminar burning velocity takes the maximum for $\phi=1.1$, as indicated in Fig. 4. However, in Fig. 10, the range of turbulence intensity that the flame can propagate for $\phi=0.9$ was the widest.

Fig. 11 shows the region of the turbulent flame structure on the regime diagram from Peters [47] in the experimental condition from $\phi=0.6$ to 1.3 . In this figure, $\delta_{F}$ is the premixed flame thickness. According to the regime diagram of Peters, in some cases of flame extinction, the turbulent flames were in the broken reaction zone regime. In the broken reaction zone regime, the flame structure is disturbed by the turbulent flow on a fine scale. Therefore, the flame surface no longer exists. All the turbulent flames that can propagate in this study were in the thin reaction zone regime. In the thin reaction zones regime, the smallest turbulent eddies become smaller than the preheating zone of the flame, but the flame structures are still larger than the reaction zone. In other words, the effect of turbulence only appears in the preheating zone of the flame and mixes the substances in the preheating zone.

where $\lambda_{f}$ is the longitudinal Taylor microscale in the ammonia/air mixture calculated using Eq. (10). When the turbulence Karlovitz number is large, the characteristic time of the chemical reaction becomes larger than the characteristic time of the disturbance. Therefore, the chemical reaction cannot be completed at the flame surface and

\subsection{Discussion on extinction limits}

The turbulence Karlovitz number at each condition was obtained by Eq. (13) as a characteristic value of the flame stretch given to the turbulent flame by the turbulent flow [45]:

$$
K a=\frac{\delta_{l} / S_{l}}{\lambda_{f} / u^{\prime}}
$$
eventually the flame is extinguished [48].

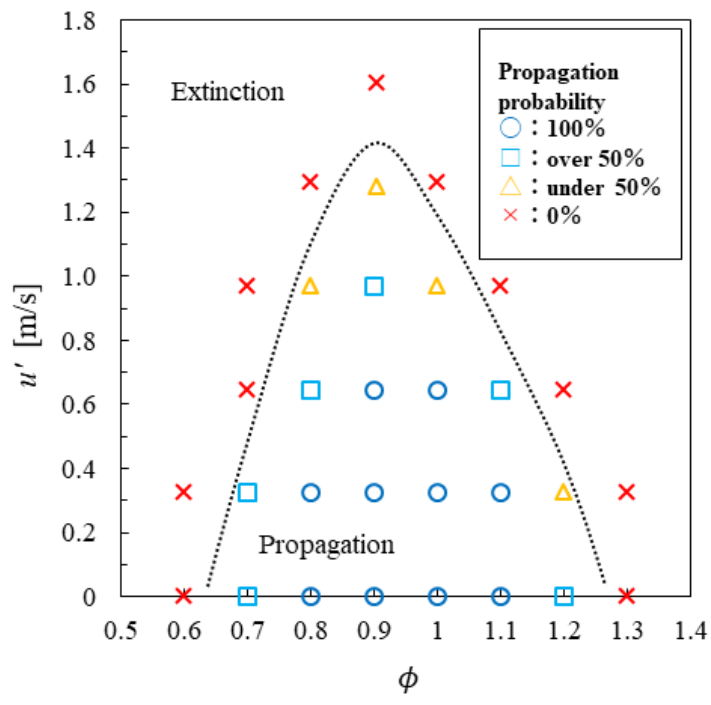

Fig. 10 Flame propagation probability map of the ammonia/air flames at the turbulence intensity, $u^{\prime}$

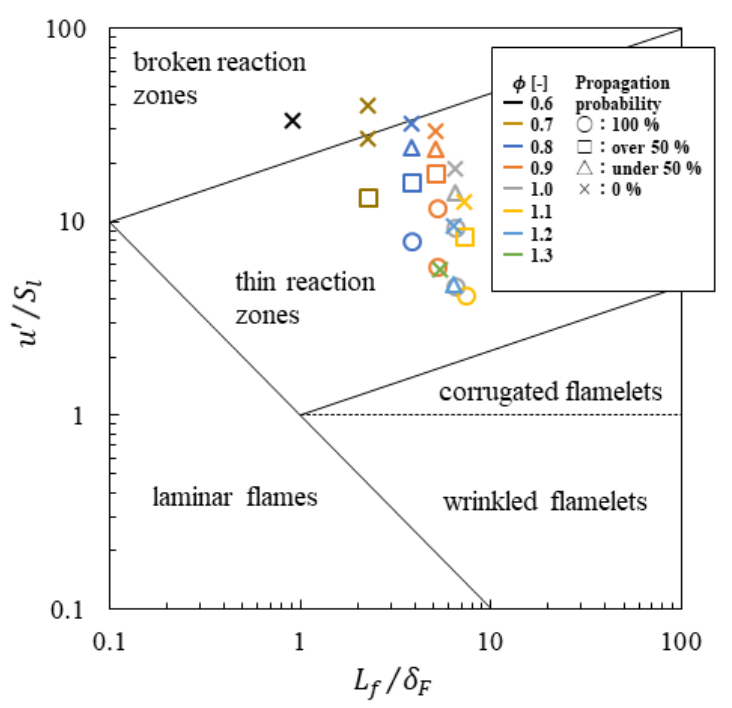

Fig. 11 Regime diagram by Peters [46] 
Fig. 12 shows the relationship between the turbulence Karlovitz number and the equivalence ratio. The turbulence

214 Karlovitz number increases with increasing turbulence intensity. The value of $K a$ under the conditions on flame 215 propagation was in the range of about 0.1 to 1.7. When the equivalence ratio was less than unity, the flame propagation 216 limit expanded to large turbulence Karlovitz number conditions. However, when the equivalence ratio was more than 217 unity, the range of the turbulence Karlovitz number under which a flame can propagate is limited even though the 218 laminar burning velocity is high. In the rich fuel mixture case of $\phi=1.2$, the turbulent flame was extinguished at a 219 turbulence intensity of $0.65 \mathrm{~m} / \mathrm{s}$. In the case of fuel-lean combustion at $\phi=0.9$ with the same turbulence intensity, 220 the turbulent flame propagated even though the turbulence Karlovitz number was virtually the same and the laminar burning velocity was 0.8 times lower compared with $\phi=1.2$. Fig. 13(a) shows the Schlieren images from ignition under lean and rich fuel conditions. The observation range of each image is $50 \mathrm{~mm}$ in diameter, i.e., the size of the observation window. In the case of $\phi=0.9$, flame propagation was observed from the center of the combustion chamber. In the case of $\phi=1.2$, the flame was observed in the same as $\phi=0.9$. However, a part of the boundary between the unburned mixture and burned gas becomes blurred around $10 \mathrm{~ms}$ after ignition. Thereafter, the blurred area increases with time, and the flame was almost extinguished around 20 ms after ignition.

The fuel-lean mixture can propagate even at a high turbulence Karlovitz number, which is most likely due to the effect of the Lewis number. When the flame surface is deformed by the turbulent eddies, the local burning velocity increases by the diffusional-thermal instability [49] for the lean ammonia/air mixture, which has a Lewis number less than unity, $L e<1$. At the local flame surface, which is convex toward the unburned mixture side, the mass diffusion toward the burned gas side excels more than the thermal diffusion from the burned gas side to the unburned mixture side. Consequently, the local flame temperature and burning velocity increases and a convex shape develops. In an opposite way, the flame temperature decreases at the local flame surface and a concave shape is also developed. Because of these developments of convex and concave structures due to the diffusional-thermal instability, the overall flame surface area increases, and the burning velocity also increases. Therefore, the flame with the fuel-lean mixture was not extinguished even in a turbulent field with higher turbulence intensity. On the other hand, the development of convex and concave structures created by the turbulent eddies were suppressed for the fuel-rich ammonia/air

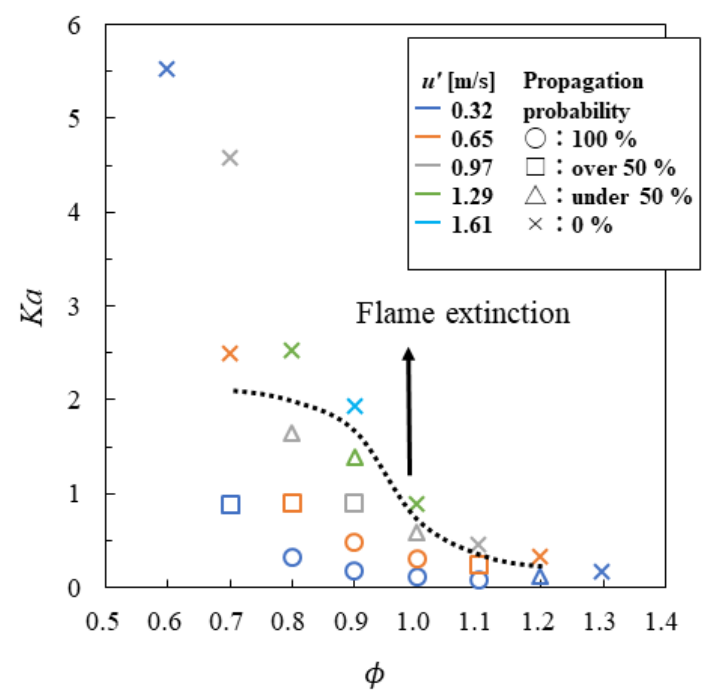

Fig. 12 Relationship between the turbulence Karlovitz number, $\mathbf{K a}$, and the equivalence ratio, $\phi$ 
mixture, in which $L e>1$. Therefore, in the case of a rich fuel mixture, the burning velocity did not increase, and the flame was easily extinguished. Fig. 13(b) shows the Schlieren images of the ammonia/air mixture for the lean and rich fuel conditions in $u^{\prime}=0.97 \mathrm{~m} / \mathrm{s}$. In both cases, the flame was finally extinguished. The differences in the process of flame extinction explained above can be observed by the Schlieren images. In the case of the fuel-lean mixture ( $\phi=0.7$ ), the local deformations of the flame surface by the turbulent eddies increased because of the Lewis number effect. In tens of milliseconds, the boundary between the unburned mixture and burned gas becomes unclear. On the other hand, the deformations of the flame surface were not grown in the fuel-rich mixture case $(\phi=1.1)$, which was caused by the effect of having a Lewis number that was more than unity [49].

Fig. 14 shows the relationship between the Markstein number and turbulence Karlovitz number under various experimental conditions. The Markstein number was obtained from the results of Hayakawa et al. [18], with an equivalence ratio range from $\phi=0.8$ to 1.2 . The Markstein number is defined as normalized flame stretch sensitivity [50]. The flame was extinguished in the case of fuel-rich mixtures with a positive value of the Markstein number even when the turbulence Karlovitz number was relatively small. As the Markstein number increases above unity, the effect of suppressing the development of irregularities on the flame surface appears remarkably, and

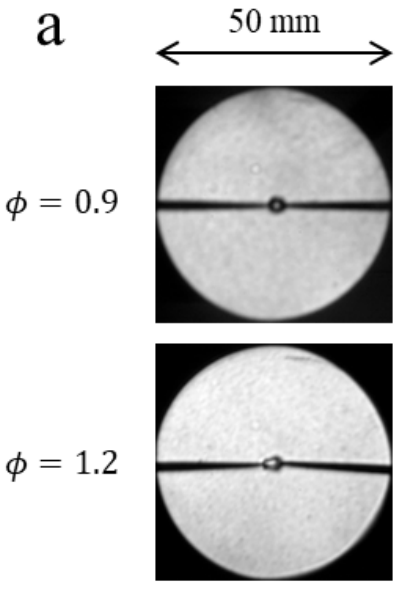

$0 \mathrm{~ms}$
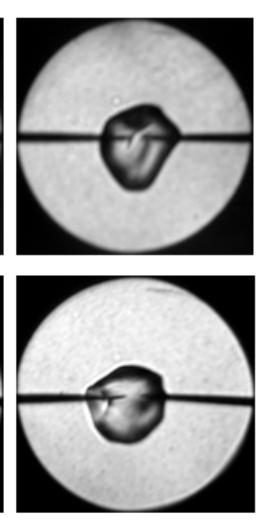

$5 \mathrm{~ms}$
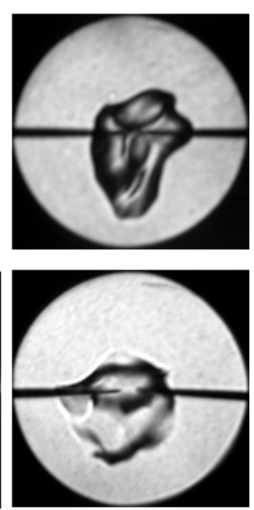

$10 \mathrm{~ms}$
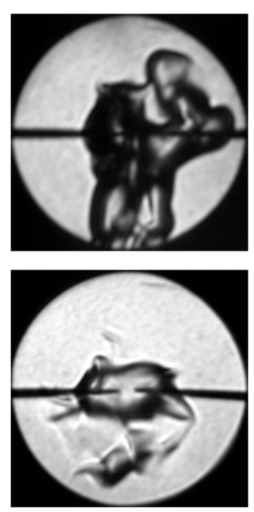

$20 \mathrm{~ms}$
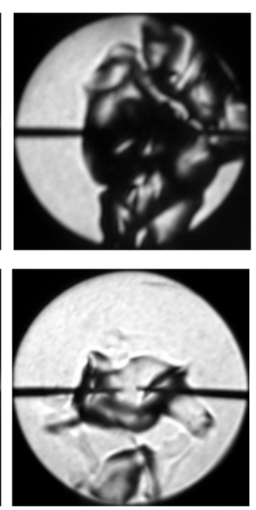

$30 \mathrm{~ms}$
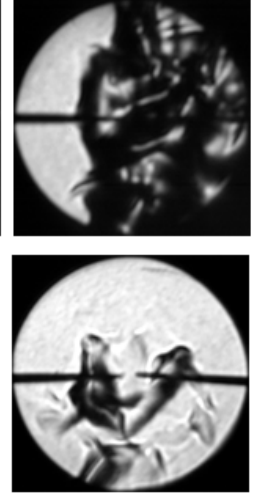

$40 \mathrm{~ms}$

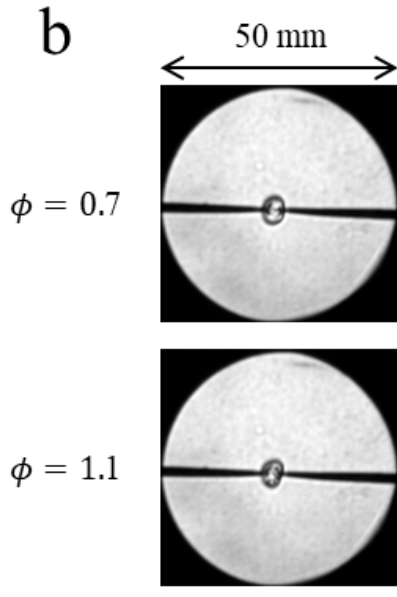

$0 \mathrm{~ms}$
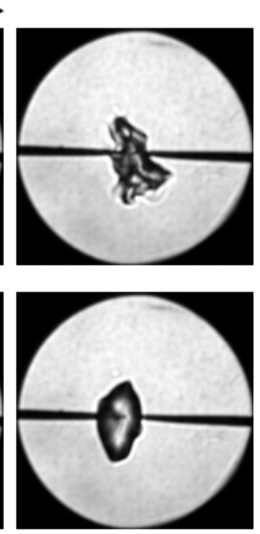

$4 \mathrm{~ms}$ $u^{\prime}=0.97 \mathrm{~m} / \mathrm{s}$
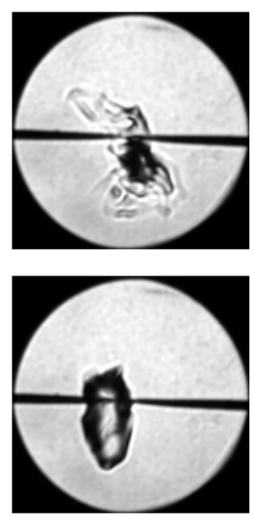

$8 \mathrm{~ms}$
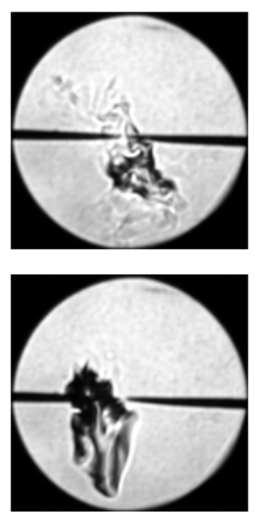

$12 \mathrm{~ms}$
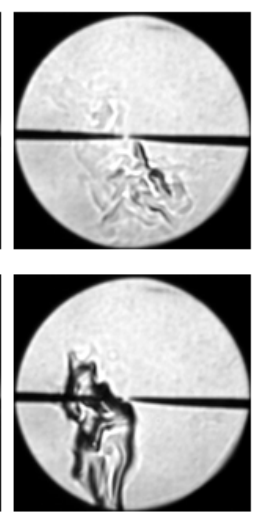

$16 \mathrm{~ms}$
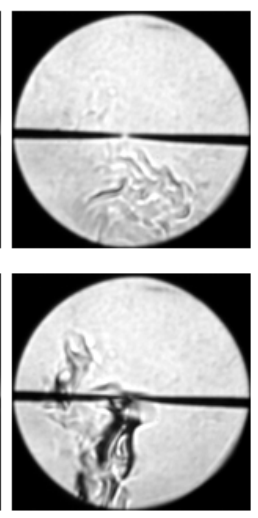

$20 \mathrm{~ms}$

Fig. 13 Schlieren images of ammonia/air mixture flame at each equivalence ratio in (a) $u^{\prime}=0.65 \mathrm{~m} / \mathrm{s}$, and (b) $u^{\prime}=0.97 \mathrm{~m} / \mathrm{s}$ 


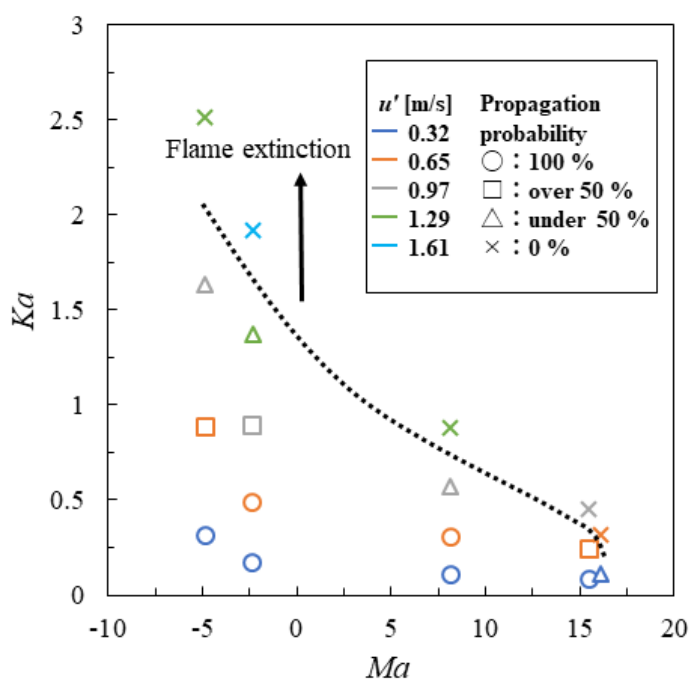

Fig. 14 Variation in the turbulence Karlovitz number, $\mathrm{Ka}$, with Marstein number, $M a$

consequently, the rich fuel mixture is extinguished easily in turbulent field around $K a=0.5$. On the other hand, in the case of fuel-lean mixtures with a negative value of Markstein number, the ammonia/air mixture propagated throughout the entire combustion chamber in spite of higher turbulence Karlovitz number. As the Markstein number decreases below unity, the developments of convex and concave structures due to the diffusional-thermal instability appear remarkably on the flame surface and the flame surface area is increased. Consequently, the flame propagation velocity increases with increases in the turbulence intensity. Therefore, the fuel-lean mixture can propagate at higher turbulence Karlovitz number compared with the fuel-rich mixture. Because of the diffusional-thermal instability mentioned above, the turbulence Karlovitz number at the flame extinction limit for the fuel-lean mixture (around $K a=1.5$ ) is higher than that for the fuel rich mixture.

\section{Conclusions}

The flame extinction characteristics of ammonia/air mixtures in a turbulent flow field were investigated by observing the flame propagation with Schlieren images. In this study, the flame extinction limit and its factor were investigated from the point of view of flame stretch and the effect of the Lewis number, using the turbulence Karlovitz number and Markstein number. The principal findings include the following.

1. The flame propagated at the highest turbulence intensity for $\phi=0.9$ even though the laminar burning velocity was at its maximum of $\phi=1.1$.

2. In the case of lean ammonia/air mixtures, the burning velocity increases with expanding flame surface area caused by the effect of the Lewis number, and the flame propagated at higher turbulence intensities. On the other hand, the burning velocity did not increase because of the effect of the Lewis number in the case of rich fuel mixtures, and the flame of the rich mixture was extinguished even at a relatively small turbulence intensity.

3. The flame extinction limit was identified by the relationship between the Karlovitz number and Markstein number. The turbulence Karlovitz number at the flame extinction limit increases with decreases in the Markstein number. This is explained by the diffusional-thermal instability of the flame surface deformed by the turbulent 
eddies.

\section{Acknowledgement}

This work was supported by JST research promotion program Sakigake (PRESTO) Grant Number JPMJPR1542 and the Collaborative Research Project of the Institute of Fluid Science, Tohoku University.

\section{References}

[1] Kobayashi Y, Tang Y, Kageyama T, Yamashita H, Masuda N, Hosokawa S, et al. Titanium-Based Hydrides as

[2] Nishibayashi Y. Development of catalytic nitrogen fixation using transition metal-dinitrogen complexes under Heterogeneous Catalysts for Ammonia Synthesis. J Am Chem Soc 2017;139:18240-6. doi:10.1021/jacs.7b08891.

[3] Ogura Y, Sato K, Miyahara S, Kawano Y, Toriyama T, Yamamoto T, et al. Efficient ammonia synthesis over a $\mathrm{Ru} / \mathrm{La}{ }_{0.5} \mathrm{Ce}_{0.5} \mathrm{O}_{1.75}$ catalyst pre-reduced at high temperature. Chem Sci 2018:2230-7. doi:10.1039/C7SC05343F.

[4] Ohki Y, Uchida K, Tada M, Cramer RE, Ogura T, Ohta T. N2 activation on a molybdenum-titanium-sulfur cluster. Nat Commun 2018;9:3200. doi:10.1038/s41467-018-05630-6.

[5] Shimoda N, Kimura Y, Kobayashi Y, Kubota J, Satokawa S. Ammonia synthesis over yttrium-doped barium zirconate and cerate-based perovskite-type oxide supported ruthenium catalysts. Int J Hydrogen Energy 2017;42:29745-55. doi:10.1016/j.ijhydene.2017.10.108.

[6] Okanishi T, Okura K, Srifa A, Muroyama H, Matsui T, Kishimoto M, et al. Comparative Study of Ammoniafueled Solid Oxide Fuel Cell Systems. Fuel Cells 2017;17:383-90. doi:10.1002/fuce.201600165.

[7] Miyazaki K, Okanishi T, Muroyama H, Matsui T, Eguchi K. Development of Ni-Ba(Zr,Y)O3cermet anodes for direct ammonia-fueled solid oxide fuel cells. J Power Sources 2017;365:148-54. doi:10.1016/j.jpowsour.2017.08.085.

[8] Valera-Medina A, Pugh DG, Marsh P, Bulat G, Bowen P. Preliminary study on lean premixed combustion of ammonia-hydrogen for swirling gas turbine combustors. Int J Hydrogen Energy 2017;42:24495-503. doi:10.1016/j.ijhydene.2017.08.028.

[9] Valera-Medina A, Marsh R, Runyon J, Pugh D, Beasley P, Hughes T, et al. Ammonia-methane combustion in tangential swirl burners for gas turbine power generation. Appl Energy 2017;185:1362-71. doi:10.1016/j.apenergy.2016.02.073.

[10] Xiao H, Valera-Medina A, Bowen P, Dooley S. 3D Simulation of Ammonia Combustion in a Lean Premixed Swirl Burner. Energy Procedia 2017;142:1294-9. doi:10.1016/j.egypro.2017.12.504.

[11] Okafor EC, Somarathne KDKA, Hayakawa A, Kudo T, Kurata O, Iki N, et al. Towards the development of an efficient low-NOx ammonia combustor for a micro gas turbine. Proc Combust Inst 2018;000:1-10. doi:10.1016/j.proci.2018.07.083.

[12] Somarathne KDKA, Hatakeyama S, Hayakawa A, Kobayashi H. Numerical study of a low emission gas turbine like combustor for turbulent ammonia/air premixed swirl flames with a secondary air injection at high pressure. 
Int J Hydrogen Energy 2017;42:27388-99. doi:10.1016/j.ijhydene.2017.09.089.

[13] Kurata O, Iki N, Inoue T, Matsunuma T, Tsujimura T, Furutani H, et al. Development of a wide range-operable, rich-lean low-NOx combustor for NH3 fuel gas-turbine power generation. Proc Combust Inst 2018;000:1-9. doi:10.1016/j.proci.2018.09.012.

[14] Boretti A. Novel dual fuel diesel-ammonia combustion system in advanced TDI engines. Int J Hydrogen Energy

[15] Reiter AJ, and Kong SC. "Combustion and emissions characteristics of compression-ignition engine using dual ammonia-diesel fuel,” Fuel, vol. 90, no. 1, pp. 87-97, 2011.

[16] Ryu K, Zacharakis-Jutz GE, Kong SC. Performance characteristics of compression-ignition engine using high concentration of ammonia mixed with dimethyl ether. Appl Energy 2014;113:488-99. doi:10.1016/j.apenergy.2013.07.065.

[17] Westlye FR, Ivarsson A, and Schramm J. "Experimental investigation of nitrogen based emissions from an ammonia fueled SI-engine,” Fuel, vol. 111, no. 2, pp. 239-247, 2013.

[18] Hayakawa A, Goto T, Mimoto R, Arakawa Y, Kudo T, Kobayashi H. Laminar burning velocity and Markstein length of ammonia/air premixed flames at various pressures. Fuel 2015;159:98-106. doi:http://dx.doi.org/10.1016/j.fuel.2015.06.070.

[19] Ichikawa A, Hayakawa A, Kitagawa Y, Somarathne KDKA, Kudo T, Kobayashi H. Laminar burning velocity and Markstein length of ammonia/hydrogen/air premixed flames at elevated pressures. Int J Hydrogen Energy 2015;40:9570-8. doi:http://dx.doi.org/10.1016/j.ijhydene.2015.04.024.

[20] Takizawa K, Takahashi A, Tokuhashi K, Kondo S, Sekiya A. Burning velocity measurements of nitrogencontaining compounds. J Hazard Mater 2008;155:144-52. doi:10.1016/J.JHAZMAT.2007.11.089.

[21] Pfahl UJ, Ross MC, Shepherd JE, Pasamehmetoglu KO, Unal C. Flammability limits, ignition energy, and flame speeds in H2-CH4-NH3- N2O-O2-N2mixtures. Combust Flame 2000;123:140-58. doi:10.1016/S00102180(00)00152-8.

[22] Okafor EC, Naito Y, Colson S, Ichikawa A, Kudo T, Hayakawa A, et al. Experimental and numerical study of the laminar burning velocity of CH4-NH3-air premixed flames. Combust Flame 2018;187:185-98. doi:10.1016/J.COMBUSTFLAME.2017.09.002.

[23] Joo JM, Lee S, Kwon OC. Effects of ammonia substitution on combustion stability limits and NOx emissions of premixed hydrogen-air flames. Int J Hydrogen Energy 2012;37:6933-41. doi:10.1016/j.ijhydene.2012.01.059.

[24] Goldmann A, and Dinkelacker F. "Approximation of laminar flame characteristics on premixed ammonia/hydrogen/nitrogen/air mixtures at elevated temperatures and pressures,” Fuel, vol. 224, no. February, pp. 366-378, 2018.

[25] Li Y, Bi M, Li B, Gao W. Explosion behaviors of ammonia-air mixtures. Combust Sci Technol 2018;190:180416.

[26] Nakamura H, Shindo M. Effects of radiation heat loss on laminar premixed ammonia/air flames. Proc Combust Inst 2018;000:1-8. doi:10.1016/j.proci.2018.06.138.

[27] Nakamura H, Hasegawa S, Tezuka T. Kinetic modeling of ammonia/air weak flames in a micro flow reactor with a controlled temperature profile. Combust Flame 2017;185:16-27. doi:10.1016/j.combustflame.2017.06.021. 
[28] Nakamura H, Hasegawa S. Combustion and ignition characteristics of ammonia/air mixtures in a micro flow 
hydrogen-air premixed propagating flames at elevated pressures. Int J Hydrogen Energy 2008;33:5842-9. doi:10.1016/j.ijhydene.2008.06.013.

393 [45] Kitagawa T, Nagano Y, Tsuneyoshi K. Study on the Effects of Pressure on Turbulent Burning Velocity of Outwardly Propagating Propane-Air Flame with Turbulence Reynolds and Markstein Numbers n.d.

395 [46] Hinze JO. Turbulence, second edition. New York: McGraw-Hill Publishing; 1975, P.208.

396 [47] Peters N. Turbulent Combustion. 2000.

397 [48] Law CK, and Sung CJ. Structure, aerodynamics, and geometry of premixed flamelets. Prog Energy Combust Sci 2000;26:459-505. doi:10.1016/S0360-1285(00)00018-6.

399 [49] Law CK. Combustion Physics. New York: Cambridge University Press; 2006, pp. 456-461.

400 [50] Lieuwen TC. Unsteady Combustor Physics (Chapter 9). Cambridge University Press; 2012. 